\title{
UM ESTUDO SOBRE AS FORMAS DE ATENÇÃO NA SALA DE AULA E SUAS IMPLICAÇÕES PARA A APRENDIZAGEM
}

Maria Helena De-Nardin

Regina Orgler Sordi

Universidade Federal do Rio Grande do Sul, Porto Alegre, Brasil

RESUMO: O presente trabalho decorre de um estudo piloto sobre a atenção em sala de aula realizado com crianças de primeira série do ensino fundamental. O objetivo foi analisar algumas das especificidades das relações ali estabelecidas que pudessem revelar-se propícias a um modo de atenção de caráter mais inventivo e problematizador. O estudo sugeriu que a construção de um espaço de comunicação dialógica favorece a capacidade atentiva dos alunos. Neste espaço, os alunos passam a experienciar a aprendizagem da atenção diversamente do modo automático como habitualmente recebem informações e são chamados a experimentar a atenção na aprendizagem. Isto se deve, principalmente, à capacidade da professora de acolher um momento de ruptura do foco atencional e manter-se num estado de abertura para $o$ inesperado.

PALAVRAS-CHAVE: aprendizagem; atenção; recognição/invenção.

\section{A STUDY ON THE FORMS OF ATTENTION IN THE CLASSROOM AND THEIR IMPLICATIONS ON LEARNING}

ABSTRACT: This paper derives from a pilot study on classroom attention undertaken with first grade children. The objective was to analyze some particularities of the relationships that were established and that may reveal propitious towards a form of attention characteristically more inventive and inquisitive. The study suggested that building an environment of dialogical communication favors the student's attentive capacity. In this environment, students are called upon to experience attention in learning which is different from the habitual manner that they are used to in receiving information. This is due, mainly, to the capacity of the teacher in giving heed to a moment of rupture from the attentive focus and keeping oneself open-minded for the unexpected.

KEYWORDS: learning, attention, recognition/invention.

No presente artigo, aborda-se a relação entre atenção e aprendizagem, partindo do pressuposto de que o modo como a atenção é compreendida implica diretamente na compreensão de seu estatuto. De um lado, podemos considerá-la condição para; de outro, podemos entendê-la enquanto efeito de uma aprendizagem. Entendida como efeito, torna-se necessário repensar seu conceito, bem como, discutir a ampliação de seu funcionamento e dos mecanismos que a ligam à aprendizagem.

Inicialmente, é importante assinalar que no contexto atual a atenção vem se revelando uma condição para que o sujeito possa dar conta de reconhecer o mundo e adaptarse a ele. Os recentes estudos de Crary (1999) mostram que desde o final do século XIX a modernidade ocidental tem produzido discursos, saberes, tecnologias e práticas sociais que entretecem uma rede de relações que se articulam e produzem mutações nas formas de perceber, conhecer e prestar atenção. A forma como prestamos atenção ao mundo emerge do estabelecimento de novas relações de trabalho, de um movimento evolutivo da tecnologia, do advento das técnicas do espetáculo e dos processos de mercantilização da sociedade contemporânea que atuam sob a lógica do capital, esta sustentada por conceitos como eficiência e rapidez, enfatizando o individualismo e a com- petitividade. Criam-se, a partir do novo cenário, outros dispositivos de constituição do sujeito que nos levam a pensar na saturação, na velocidade e no excesso, características marcantes da era da informação. Estes dispositivos obrigam-nos a atuar de determinada maneira para que possamos permanecer no mundo e interagir com ele. Para isto precisamos responder com grande capacidade de focalização em pontos múltiplos e com avidez de novidade. Produzem-se, então, exigências como pontualidade, focalização e reconhecimento. Desde aí, a atenção é condição para a realização de tarefas e para o processamento de informações.

Quando nos referimos à atenção no âmbito escolar, na maioria das vezes o termo vem associado aos diagnósticos de déficit atencional e hiperatividade que, a partir dos anos 90, começaram a gozar de importante prestígio nos meios médicos e nas escolas, chegando às famílias. Naquele período houve uma explosão de diagnósticos, cujo instrumento, o Diagnostic and Statistical Manual of Mental Disorders (American Psychiatric Association, 1994), está constituído por um inventário de dados comportamentais. As características propostas pelo DSM IV - dentre as quais estão baixo rendimento na realização das tarefas, falta de atenção, dificuldade de seguir regras, impulsividade-hiper- 
atividade - observáveis na escola, no ambiente de trabalho, na clínica e em situações familiares, sustentam uma concepção com ênfase no adoecimento do indivíduo, cujos distúrbios podem ter causas múltiplas: tanto da ordem do desenvolvimento ou da estruturação orgânica, quanto da ordem do emocional ou relacional. São causas de caráter individual, avaliadas a partir de uma abordagem psicológica e epidemiológica constitutivas de um domínio da realidade onde a cognição é entendida enquanto capacidade de solucionar problemas e a atenção, por sua vez, tem papel específico: o controle do comportamento e a realização de tarefas. Tomada como condição para a aprendizagem, sua análise se restringe a uma atenção voltada para a captação e busca de informações. A partir desta lógica, os sujeitos com queixas de falta de atenção são normalmente situados num quadro de patologia, onde o adoecimento é produzido no indivíduo e pelo indivíduo.

Neste artigo não se tem o propósito de entrar na discussão, propriamente dita, dos diagnósticos de déficit de atenção. A atenção, na atualidade, levanta uma série de questões que remetem a diferentes caminhos: biológicos, fisiológicos, psicológicos e culturais. Verifica-se um paradoxo no que diz respeito ao conceito de atenção subjacente àquela requerida para a aprendizagem e à que é objeto de estudo no campo dos déficits atencionais. A categoria conhecida como Transtorno de Déficit de Atenção implica uma noção de atenção como função cerebral mensurável, responsável pela capacidade do sujeito de manter a seletividade e a constância da atenção. Entretanto, estudos mais recentes (Crary, 1999; Corea \& Lewkowiz, 2005; Kastrup, 2004) apontam para o fato de que os modos como ouvimos, olhamos ou nos concentramos em qualquer coisa têm um caráter profundamente histórico. Entende-se, em acordo com estes autores, que nossa maneira de estarmos atentos não é ditada pela biologia ou por algum fenômeno imediato, mas é mediada por nossas experiências de vivências num determinado contexto histórico-cultural que caracterizam nossa forma de atenção ao mundo e a nós mesmos.

A partir dessa abordagem, propõe-se um avanço na discussão no sentido de pensar uma outra face do processo atencional: de uma atenção requerida em sala de aula e caracterizada pelo ato de prestar atenção para uma atenção cujas raízes da palavra, segundo Crary (1999), nos remetem a duas inflexões. Por um lado, ressoam com um sentido de "tensão", de "ser esticado, estendido" e, por outro, de "esperar". Isto implica a possibilidade de uma "fixação, de segurar algo em contemplação", em cuja experiência o sujeito atento está "tanto imóvel, quanto sem fundação." Trata-se de um movimento continuado, que emerge entre diferentes experiências vividas pelo sujeito, e de um movimento de detenção/fixação, condição necessária para uma produção de sentido. Ou seja, há um contínuo atenção-desatenção, quando a desatenção, caracterizada por uma suspensão no tempo, permite ao sujeito um momento de ruptura com o aqui e o agora sem perda da força de relação com o objeto/foco inicial.

Como consequiência dessas reflexões surge a proposta de observar situações em sala de aula que possam revelarse práticas construtoras de um modo de atenção de caráter mais inventivo, capazes de novas aberturas. Para tanto, desenvolveu-se um estudo piloto com o objetivo de relatar as observações e reflexões que podem servir de indicadores para o encontro com as respostas às perguntas que nortearam o estudo: Quais as formas de atenção encontradas na sala de aula? Que consequiências advêm delas para o processo de aprendizagem? O que se passa num espaço onde se mostra um modo de atenção necessário à invenção?

A partir destas e outras questões, pretendeu-se, num primeiro momento, pensar sobre os diferentes fluxos de atenção requeridos para dar conta de uma aprendizagem capaz de inventar. Num segundo momento, desliza-se para a temática central a qual diz respeito à possibilidade de considerar a atenção como um dos aspectos do processo cognitivo que pode se constituir a partir de diferentes experiências de subjetivação possíveis de serem vividas no contexto escolar. A seguir, apresentam-se recortes de cenas de sala de aula que são tomados para auxiliar a identificar situações em que se mostram os distintos modos de atenção, o recognitivo e o inventivo e, a partir dessa identificação, traçar as características de cada momento que os possibilitou.

\section{As Formas de Atenção na Aprendizagem}

Quando Kastrup (1999) estuda a invenção, introduzindo no conceito de cognição o problema do tempo e do coletivo, esse conceito amplia-se, não se restringindo apenas à inteligência ou à solução de problemas. A autora vai diferenciar recognição e invenção, sendo que será a natureza inventiva da cognição que possibilitará pensar um sujeito capaz de "inventar a si e ao mundo." Nesse processo, é a atuação do sujeito que possibilita novas formas de conhecer, de pensar e de produzir outras configurações de mundo. Recognição e invenção ocuparão lugares distintos, mas complementares no processo da cognição.

As experiências de recognição permeiam nosso cotidiano e nos permitem o reconhecimento dos objetos de modo que possamos ter um bom desempenho diário diante das situações com as quais nos deparamos. Nossa capacidade de busca de solução para os problemas experimentados em determinado contexto fica assegurada graças a tais experiências. Elas são, conforme definido por Deleuze, "o exercício concordante de todas as faculdades sobre um objeto suposto como sendo o mesmo: é o mesmo objeto que pode ser visto, tocado, lembrado, imaginado, concebido" (1988, p. 221). Experimentamos diariamente situações em que nos vemos às voltas com distintas atuações 
recognitivas. Seria impossível nos movermos no mundo sem esta habilidade. Como ir à escola sem poder identificar o caminho, os sinais de trânsito que nos possibilitam a travessia das ruas, o ônibus ou transporte escolar que nos conduz até onde desejamos? Somos orientados por esta capacidade recognitiva. Solucionamos nossos problemas, graças a ela. Todavia esta experiência de aprendizagem não pode explicar o surgimento da novidade.

Neste estudo, inventar, cuja palavra se origina do latim invenire, significa compor com "restos arqueológicos" (Kastrup, 1999), o que quer dizer que há uma prática, uma experimentação, um "trabalho com restos" que num momento determinado - o momento da invenção -, quando da remoção das camadas, aquilo que se encontrava oculto revela-se. Esta prática conduz a um resultado imprevisível, marcado pela produção tanto do sujeito quanto do objeto, num momento de encontro com o inesperado quando a invenção, por seu caráter de problematização, opera com sua tendência crítica em que o comum é tornado incomum. Nessa experiência, sensibilidade, memória e atenção, por exemplo, percorrem caminhos distintos, produzindo um estranhamento que ultrapassa o reconhecimento e força a aprendizagem que, segundo Deleuze (1988), começa nesse exato momento.

Inspirada na linguagem bergsoniana, Kastrup utilizase do termo "problematização" para mostrar que a cognição inventiva começa com a invenção de um problema que não é de uma ordem negativa ou de necessidade, mas "consiste numa problematização da subjetividade, uma exigência de criação” (1999, p. 101). Colocar o problema para Bergson, diz Deleuze, "não é simplesmente descobrir, é inventar. A descoberta incide sobre o que já existe, atualmente ou virtualmente; portanto, cedo ou tarde ela seguramente vem. A invenção dá o ser ao que não era, podendo nunca ter vindo.” Então, Deleuze aponta para o fato de que para aquele filósofo a noção de problema tem suas raízes na "própria vida e no impulso vital: é a vida que se determina essencialmente no ato de contornar obstáculos, de colocar e resolver um problema” (1999, p. 9-10).

Tomando as duas características da invenção - imprevisibilidade e problematização - pode-se pensar em ampliar o conceito de atenção, situando-a além do ato de prestar atenção a tarefas, objetos ou situações externas. A atenção poderá ser, então, um ato de encontro com experiências pré-simbólicas e de invenção de problemas. Sendo assim, a atenção poderá ser pensada não apenas como um processo único e homogêneo, mas como um movimento que se modula em diferentes fluxos e por isto pode mostrar-se funcionando de formas distintas.

Da forma como se observam as atuações no espaço escolar, verifica-se que na sua maioria elas estão apoiadas numa perspectiva segundo a qual aprender associa-se a uma adaptação a um mundo pré-existente (Sordi, 1999).
É preciso ensinar às crianças tudo aquilo que lhes possibilita viverem adaptadas ao mundo onde estão inseridas. Resume-se a aprendizagem a uma transmissão de conhecimentos acumulados historicamente que indubitavelmente são importantes, mas não suficientes. A partir desse pressuposto, a atenção focalizada surge como condição fundamental para a aprendizagem: quanto maior o poder de manter o foco em determinado objeto, maiores as chances de sucesso infantil.

Como as modalidades de ensino estão basicamente fundamentadas em processos de recognição, o ato de prestar atenção está associado a eles como uma das suas condições indispensáveis. Ato que, conforme aqui está sendo entendido, limita-se ao processo de focalização que não deve ser confundido com concentração, pois, de acordo com Kastrup (2004) pode haver focalização sem concentração, da mesma forma que pode haver concentração sem focalização, como veremos adiante.

Na perspectiva recognitiva de aprendizagem não está implicada necessariamente uma concentração, porque a concentração supõe a possibilidade de ir além da capacidade de executar tarefas; supõe uma possibilidade inventiva e, portanto, uma cognição enquanto capacidade problematizadora. Neste caso, a concentração, ao contrário do que normalmente se pensa, precisa recorrer à possibilidade de distrair-se, sendo que o distrair-se é experimentado num "colapso", numa "rachadura" (Varela, 2003), ou ainda num momento de "descontinuidade" (Bergson, 1907/2005). Dá-se um movimento em que o sujeito pode e necessita, se falamos em invenção, transitar entre atenção e desatenção. $\mathrm{O}$ encontro se dá entre o passado inteiro que acompanha o sujeito e o instante presente. Trata-se de uma experimentação nova que, ao sofrer uma ruptura na continuidade, escapa ao instante presente, ao momento da focalização, mas mantém um elo que reconduz o sujeito e possibilita que o problema seja inventado.

No momento da concentração haverá uma inibição do foco e uma renúncia a perseguir o resultado útil da percepção, acontecendo um novo circuito que permite ao sujeito uma relação consigo e cujo progresso da atenção terá por efeito criar o novo. Há um intervalo, mas o sujeito se mantém ligado com a noção anterior; ao passo que na focalização, ao ser rompido o foco, não se mantém qualquer conexão com o que vinha atendendo anteriormente. Na concentração, o sujeito experimenta aquilo que Bergson (1896/1999, 1907/2005) chama de "duração", cujas características fundamentais são a continuidade e a heterogeneidade, pois falamos de experiências que conservam atual e atuante o passado no presente, ao mesmo tempo em que introduzem distinções, produzindo o novo.

Isto posto, entende-se que subjacente ao apelo de prestar atenção da escola, está um conceito que faz referência a um movimento de detenção, não de uma capacidade de 
concentração. Detenção não tem a ver com "duração". Detenção tem relação com fixação do foco, enquanto concentração tem a ver com uma certa abertura que, em seguida, revela-se como distração.

Assim, de um lado lidamos com a maneira como a atenção é problematizada hoje, enquanto um elemento necessário para o reconhecimento da informação; de outro lado, nos deparamos com os estudos da consciência em que a atenção que emerge como um estado possível e necessário para a invenção é uma atenção capaz de transitar entre estados de atenção focalizada e atenção distraída. Nesta última, encontramos atenção como uma constelação de experiências e práticas, muito mais que uma questão de fixação, de olhar ou de sujeito como espectador.

\section{Delineando as Formas de Atenção $e$ as Interações Escolares}

Conforme anunciado, trataremos, agora, de analisar os momentos de uma experiência de aprendizagem escolar que se revelaram propícios para a invenção, e os seus desdobramentos.

Os estudos iniciais foram feitos a partir de observações, em sala de aula, das relações aluno-professora-objeto do conhecimento, que totalizaram aproximadamente cem horas. Selecionaram-se duas turmas de primeira série do ensino fundamental de escola pública e privada. Uma delas, pelo encontro com o interesse da direção e outra foi o resultado de uma escolha, cujo critério levou em consideração o conhecimento prévio que se tinha do trabalho da professora, que se revelara, em situação anterior a esta pesquisa, voltado para a constituição de um espaço de escuta e acolhimento do pensamento da criança.

O caminho metodológico adotado tem raízes nas pesquisas de caráter qualitativo, com uma abordagem de inspiração etnográfica, utilizando, como instrumentos, notas de campo, áudio-gravações, registros dos diálogos e depoimentos espontâneos de alunos e professoras.

Os estudos e reflexões desses registros sugeriram a indicação de um sinalizador - o "breakdown" - para o estudo de momentos de ruptura da atenção focalizada capazes de novas aberturas.

Varela (2003) utiliza o termo "breakdown" para referirse a uma espécie de abalo ou colapso, ou ainda rachadura na continuidade cognitiva. Este movimento, segundo o autor, potencializa o nascimento do novo, pois, embora pareça paradoxal, o colapso não rompe o fluir da conduta, mas o assegura, tendo em vista que provoca uma certa afecção no sujeito. O que acontece no momento do colapso não é um rompimento, mas um diálogo entre uma situação específica vivida e a capacidade de o sujeito exercer ações apropriadas em determinadas circunstâncias, resultado da maneira pela qual "corporifica" uma série de atuações recorrentes, constituídas sócio-historicamente.
Neste estudo, define-se "breakdown" como efeitos que se expressam na ação dos sujeitos frente a momentos de ruptura do foco atencional. Os dois subtipos foram assim caracterizados:

1. Breakdown que resulta em momentos de problematização: colapsos que articulam diversas situações sóciocognitivas experienciadas pelos sujeitos, em sala de aula, e que são responsáveis pelo "lado autônomo e criativo da cognição" (Varela, 2003). São considerados os momentos de atenção inventiva;

2. Breakdown que resulta em momentos divergentes da problematização: colapsos que, ao emergirem das diversas situações sócio-cognitivas experienciadas pelos sujeitos, em sala de aula, não são acolhidas e promovem um retorno ao foco atencional e um não acolhimento da problematização.

Após a identificação do surgimento dos sinalizadores dentro do contexto escolar, escolheu-se uma situação ilustrativa de cada um dos subtipos. Tais cenas foram privilegiadas, pois caracterizam dinâmicas de atuação distintas e permitem tecer algumas considerações que tornam possível refletir e discutir a tessitura da relação constitutiva entre atenção e aprendizagem no espaço escolar.

Na primeira cena, podemos ver a professora escrevendo a atividade no quadro. Há três colunas: de um lado está uma coluna de palavras; no meio, números correspondentes à quantidade de letras que formam a palavra e, na coluna da direita, um desenho representando a palavra da esquerda. As crianças deveriam unir com uma linha (ligar) o nome ao número e ao desenho. Durante certo tempo, elas trabalharam em seus cadernos. Em seguida, a professora solicita a atenção da turma e segue-se um diálogo que, analisado conforme a proposta de identificação dos sinalizadores a partir da análise do fluxo das falas, sugere a presença de um breakdown que se passa entre as falas.

A palavra hospital compunha a lista proposta para o trabalho. Ao ser solicitada a identificação do desenho que deveria ser unido à palavra hospital, o aluno J. responde "menino". A professora, com uma expressão facial de espanto e franzindo as sobrancelhas, diz: "Ah? Menino? Se é hospital, tenho que ligar com o prédio que parece hospital". Enquanto liga o número ao desenho, a professora pergunta: "Não estavas prestando atenção, J.?"

No primeiro momento, quando J. diz "menino" para fazer referência ao hospital, poderíamos pensar na possibilidade de que ele experimentou um momento de distração ao deparar-se com a palavra hospital. Hipoteticamente, a palavra produziu uma certa afetação em J. que o remeteu a pensar em menino, talvez uma experiência já vivida. Se atentarmos para a relação de sentido entre hospital e menino, podemos inferir que J. experimentou uma distração sem perder o ponto de encontro com o objeto em es- 
tudo. Esta distração do aluno poderia sugerir que o garoto estava atento ao que se passava em aula. Poder-se-ia inferir que houve um momento de trânsito entre a pergunta e uma experiência já vivida por ele, ou seja, um momento de "duração" que o fez desviar do foco que previa o reconhecimento do desenho e fazer referência à outra coisa: menino em lugar de prédio.

Entretanto, é importante assinalar que se observa uma pausa: a pergunta da professora (“Ah? Menino?”) e sua expressão facial (espanto e franzimento das sobrancelhas) indicam que a professora encontrou-se diante de um colapso cognitivo: uma resposta "menino" para o que deveria ser "prédio que parece hospital". Ela não consegue acolher este momento de ruptura do foco atencional e imediatamente trata de retomá-lo, resgatando o objeto perdido (prédio). A perplexidade observada na sua expressão facial e verbal sugeriu um momento de breakdown, que acabou por não resultar em momento de problematização. Por não poder sair do foco recognitivo, a professora não pôde acionar sua possibilidade criadora.

Seguindo a leitura do diálogo, observou-se um padrão recognitivo marcado pela obrigação determinada aos alunos de descobrir a resposta que a professora desejava ouvir deles. Diante da resposta errada, ela mesma tratou de assinalar a resposta certa, mantendo um padrão linear pergunta da professora-resposta do aluno-feedback da professora (Sordi, 1999), encerrando a conversação. O que se identifica nesse contexto é uma troca objetiva de informação, e não a tentativa de buscar um sentido comum. Observa-se em outros momentos do diálogo, quando as respostas não completam a pergunta da professora na forma esperada, que ela acaba por repetir a resposta certa, desqualificando as falas das crianças.

A partir das considerações feitas após a identificação do sinalizador e sua análise, procurou-se delinear as práticas possibilitadoras da construção do espaço subjetivo que propiciou tal experiência. A análise dos registros permitiu o encontro com um modo de atuação que se denominou dinâmica de conversações informacional. Maturana (1998, 2001, 1973/2002) utiliza-se do termo "dinâmica das conversações" para referir-se a um modo de existir humano, ou seja, um modo de operar no qual a linguagem se define como aquilo que se passa "entre" duas ou mais pessoas no "interatuar". A partir desse conceito e do que Corea e Lewkowicz (2005) propõem como "comunicação informacional”, a dinâmica de conversações informacional será definida, neste estudo, por sua preocupação com a informação. Nesse modo de atuação, se sobressai um monólogo, situação em que os sujeitos não se dirigem uns aos outros, não falam uns com os outros, mas falam para os outros. Existe um foco de atenção comum, mas não há coordenação de pontos de vista que possa produzir um pensar sobre o pensamento, de forma que as verdades são apresentadas como questões imutáveis.
Então, seguindo a leitura dos diálogos e notas de campo dessa primeira cena, observa-se que as atuações estão caracterizadas por sua linearidade, pela preocupação com a garantia da resposta certa e por seu caráter de representação. Tendo em vista o modo de atuação desses sujeitos em sala de aula, o breakdown não encontrou um espaço para produzir novidade, pois se deparou com uma conduta que a neutralizou. Quando J. fala “menino” para fazer referência a hospital, ele cria uma possibilidade de tornar pensável algo que na proposta recognitiva está ausente. A proposta recognitiva, por estar fundamentada na hipótese baseada no conhecimento como representação, ${ }^{1}$ não toleraria, e não tolerou, um menino ocupando o lugar de um prédio que deveria representar um hospital. Para poder atuar de forma divergente, a professora precisaria sair de um momento de focalização e permitir-se experimentar certa abertura para o inesperado. Como a proposta recognitiva exige uma experiência de focalização da atenção no objeto em questão, fica inviável a criação de um espaço para a novidade que só aparece em momentos de distração. Assim, a invenção fica obstaculizada por uma dinâmica de conversações informacional.

Ao se depararem com um modo de ensinar que não as acolhe/escuta, mas apenas lhes informa, as crianças encontram-se num espaço que reproduz, em um grau diferenciado, os modos de experimentar o mundo atual. Neste caso, fala-se da exigência de uma atenção focada, típica do prestar atenção que, na escola, junto com o ficar quieto transforma-se no principal dever dos alunos. Ao referirse à expressão prestar atenção, Fernández interroga-nos e nos convoca a pensar sobre o uso do termo no meio escolar.

O que é que "se paga" quando "se presta" atenção? Quem paga e por que deveria pagar alguma coisa? O aluno está em dívida quando o professor pede "pay (paguem) attention, please”? Quando o professor não fala inglês, mas português, pede "prestem atenção", que vem de prestar/render contas a outro... Quem paga, o que paga e a quem paga? (2001, p. 214).

A convocação para que os alunos prestem atenção, normalmente, vem acompanhada de um olhem para cá. Olhar, então, é sinal de atenção, e esse olhar tem endereçamento certo: para a professora e para o quadro-negro. A pergunta Qual o espaço de invenção que ainda resta para alunos e para professores? fica reverberando quando as experiências de aprendizagem se restringem à recognição.

Propõe-se, agora, refletir sobre a segunda cena: a professora reúne as crianças em frente à sua mesa. Toma uma folha na mão e mostra-a, solicitando que todos a olhem. Há um desafio, um problema para resolver: "Vamos imaginar que tem umas crianças escondidas atrás desse muro. Olhem as mãozinhas delas aqui. Eu quero saber quantas 
crianças estão escondidas. Mas, olhem só, isto não é suficiente. Eu quero saber como vocês pensaram pra descobrir isto."

Como no primeiro protocolo, aqui também se tentou identificar o sinalizador. O sinalizador, que será descrito a seguir, foi selecionado por possibilitar a descrição do fenômeno que se chamou breakdowns que resultam em momentos problematização.

Depois de certificar-se de que as crianças haviam dialogado e encontrado a solução, a professora propõe que cada grupo revele como fizera tal descoberta. É nisso que ela se concentra, e a análise das transcrições das falas nos permite observar que naquele espaço de diálogo se passa algo que parece ser uma experiência que força a pensar: marca da problematização.

Ao ouvir a afirmação dos colegas de que havia cinco crianças atrás do muro e o relato de que sua descoberta fora feita contando as mãos de dois em dois, o aluno L. comenta: "Uma pessoa pode tá se segurando só com uma mão." Estava lançado um problema...

A problematização não foi apenas um mero movimento do menino. Algo no desenho (objeto) o força a problematizar. Num primeiro momento, L. deixa-se afetar pelo desenho e pelo que ele pode representar. Olha-o, escuta os colegas, mas não compartilha suas idéias. Permanece sozinho, durante um bom tempo, observando sua folha, para só depois integrar-se ao grupo. No momento seguinte, quando da apresentação de um grupo, L. olha atentamente para os colegas e para a folha que está sendo apresentada à distância. Possivelmente seu pensamento estava sendo forçado a procurar o sentido do que se mostrava entre o desenho e a fala dos colegas. Ao fazer essa procura, L. inventa um novo problema.

Embora houvesse vários indícios apontando para o fato de que se poderia reconhecer cinco pessoas representadas no desenho, L. afasta-se desse esquema recognitivo. Parece que não é a presença de um objeto desconhecido, tampouco a identidade do objeto que força L. a pensar, mas um sentido que escapa ao reconhecimento e que só se viabilizou porque o menino não manteve o foco de sua atenção no familiar (cinco pessoas). Ao deixar-se afetar, L. propõe que se possa pensar em outra coisa.

O que nos interessa aqui é assinalar a abertura da professora para a fala de L. Ninguém, além dela, escutou o que o menino dissera. Se ela estivesse interessada apenas na solução do problema, poderia ter ignorado o assinalamento de L. Todavia, a professora o acolhe e cria um espaço onde todos possam seguir pensando junto com ele, acionando, não só a possibilidade criadora das crianças, como a sua própria: improvisa um muro-cartolina e cria uma cena que dramatiza com seus atores mirins. Ela deixase tocar pela novidade proposta por seu aluno e compartilha a experiência de aprendizagem.
É de igual importância ver o que se passou antes do breakdown. O que propõe a professora? "Tem umas crianças escondidas atrás desse muro. Eu quero saber quantas crianças estão escondidas. Mas, olhem só, isto não é suficiente. Eu quero saber como vocês pensaram pra descobrir isto." A consigna "eu quero saber como vocês pensaram" cria um espaço para muitas possibilidades, onde a aprendizagem é o resultado da experiência de cada um na relação com o conhecimento, consigo e com os outros. Não se trata apenas de descobrir o que está representado ("isso não é o suficiente"), mas de saber, antes de tudo, o que cada um pensou. Esta concepção se confirma no fechamento da discussão feito pela professora, após uma conversa repleta de idéias: "Então, podemos pensar dos dois jeitos." Um pouco antes, ela diz: "L., tu teve uma idéia!" Percebe-se que a professora intervém a partir de uma proposta de experiência de autoria de pensamento. A solução do problema é parte importante do processo, mas não é a principal.

É possível observar no decorrer do diálogo que as crianças mantêm seu foco de atenção no reconhecimento de indícios fornecidos pelo desenho, procurando argumentos que justifiquem suas respostas. Para desestabilizar suas certezas, a professora propõe uma simulação: cria um muro-cartolina. Mesmo assim, as crianças permanecem fiéis ao que o desenho lhes sugeriu no primeiro momento e ficam presas àquilo que podem reconhecer como sinais: no desenho eram os polegares e a distância entre os pares das mãos que indicavam algo; agora, na cena do muro-cartolina, são os tamanhos e as cores das mãos. A professora, no entanto, não encerra a discussão antes que todos os argumentos tenham sido testados e segue fazendo proposições. Até que, finalmente, após a dramatização, ela confirma: "Eu concordo que parece que tem uma e na verdade tem duas pessoas aqui atrás." Mas, o assunto não estava encerrado. Um aluno volta a argumentar, agora comparando a cena com o desenho: "Aí não tá separado. Aqui nessas duas tá." Sobre o que a professora então conclui: "Sim. As mãozinhas do desenho tão mais pertinho e depois tem um espaço no meio das outras. A profe queria que vocês pensassem que cada pessoa mostrava suas duas mãos." Mesmo dizendo isto, ela mantém a autoria do pensamento de L. ao dizer "L., tu teve uma idéia."

Seguindo a proposta de delinear as práticas possibilitadoras da construção do espaço subjetivo a partir da identificação e análise do sinalizador, encontrou-se, na análise desse protocolo, o que neste estudo se denominou dinâmica de conversações comunicativo-dialógica e se caracterizará pelo estabelecimento do encontro de uns com os outros, onde cada sujeito tem a possibilidade de mostrarse pensando. Neste modo de operar, a atenção é compartilhada e a comunicação vai se constituindo de sentido a partir da coordenação de pontos de vista, devendo possibilitar situações para a invenção. A instalação de uma dinâ- 
mica comunicativo-dialógica implica na valorização do pensamento, uma postura corporal que sugere acolhimento e pertencimento, aceitação do outro como legítimo na relação e a vivência de experiências regidas pelo princípio da cooperação e da reciprocidade.

Observa-se, no protocolo, que nenhuma proposição é rejeitada pela professora, todas elas são validadas e todos seguem pensando juntos. Há uma integração dialógica que só é possível pela via do respeito ao ponto de vista do outro, de forma que o conhecimento vai sendo construído a partir da diversidade, sem o objetivo de homogeneizar. Parecia muito difícil para as crianças pensarem outra possibilidade que não aquela cuja resposta encontraram e confirmaram. A professora, aberta ao breakdown, dá-lhe passagem e mantém sua atenção suspensa, o que viabilizou a experiência de troca vivida por todo o grupo. Percebe-se uma diferença significativa entre um encontro onde acontece algo da ordem da troca de informações e um encontro onde acontece uma experiência de comunicação-dialógica.

As questões que se colocam a partir de agora são: Como, então, será possível aprender a transitar entre uma experiência de atenção focalizada e uma experiência de atenção inventiva? Será a escola um campo de possibilidades? Que experiências ela deve proporcionar aos alunos cuja subjetividade se constituiu a partir das experiências cotidianas de hiperestimulação?

\section{Considerações Finais}

Considerando-se o exposto, parece que as experiências de práticas pedagógicas sustentadas por uma concepção de aprendizagem processual têm grandes chances de possibilitar a construção de uma capacidade de atenção distinta daquela necessária para dar conta da informação e da qual boa parte dos alunos carece.

A capacidade atencional, tanto quanto a capacidade de brincar se aprendem; porém, ninguém pode ensiná-las. Isto reveste a função de quem ensina de uma importância singular, já que não existem conteúdos, tampouco métodos que possibilitem estas aprendizagens. Elas somente são possíveis na relação com um outro que acredita na capacidade pensante do sujeito, seja ele criança, jovem ou adulto.

Uma relação de tal ordem não pode ficar engessada num modo de comunicação-informacional, pois a uma fixação na informação corresponde uma capacidade de produzir o mesmo, de reproduzir e, para isto, é demandada uma atenção focalizada que se distancia da capacidade de perguntar, de problematizar, de inventar; conseqüentemente, ela não supõe um outro pensante na relação. Uma relação da ordem da dialogicidade está aberta para a aceitação do outro como legítimo na relação e, portanto, compartilha a diversidade. Numa cena escolar cotidiana onde o diálogo está presente, é possível construir um ca- minho para tratar do sentido como invenção do processo de aprender, em que cognição se mistura à experiência dos cuidados de si. $^{2}$

Se uma subjetividade se constitui a partir do modo de experimentar a si e ao mundo, então podemos entendê-la como uma construção feita a partir de um conjunto de operações. Que operações podem ser feitas no espaço escolar para que a capacidade atentiva dos alunos possa transitar entre focalização e concentração? Em outras palavras: o que fazer para possibilitar a experiência de uma atenção capaz de novas invenções?

Ao entendermos as práticas pedagógicas como uma experiência escolar dialógica, ${ }^{3}$ seremos conduzidos a levantar a hipótese de que estas práticas exigem doses de atenção distintas daquela que a maioria das crianças e adolescentes experimentam hoje. Para que seja possível um enfrentamento com os contextos e práticas da vida diária, parece necessário o cultivo das duas possibilidades de atenção, a recognitiva e a inventiva, mas somente a última seria capaz de produzir consciência e memória. Experiências rotineiras de acolhimento de breakdown em sala de aula poderiam possibilitar o exercício de uma certa hegemonia da consciência sobre os apelos sensórios. Teríamos, neste caso, não mais a dispersão, mas uma atenção consciente.

\section{Notas}

1 Esta hipótese entende o conhecimento apenas como a representação fiel de uma realidade independente do conhecedor. Portanto, para seus defensores, o mundo é pré-dado em relação à experiência humana, ou seja, ele contém as informações e nossa tarefa seria extraí-las por meio da cognição. Varela, Thompson e Rosch (2003).

2 A expressão "cuidado de si” está sendo utilizada no sentido dado por Foucault $(1985,2004)$ em seus últimos escritos, que nos remetem a entendê-la como uma relação mais criativa que o sujeito estabelece consigo, que se desdobra numa maneira como ele pode se constituir, numa relação com o outro. Não se trata, portanto de uma vaga preocupação com cuidados com o corpo ou com a satisfação imediata das necessidades da forma como tem sido significada nas últimas décadas.

3 O termo "experiência escolar dialógica" faz referência a práticas de interlocução onde duas pessoas se abeiram da mesma realidade com o intuito de se acercarem o mais possível de um sentido compartilhado. O diálogo sempre envolve um dos interlocutores tanto quanto o outro. Cada interlocutor fala com o outro, e não para ele. Num diálogo estão implicadas ações como concordar, responder, perguntar, discordar, prestar atenção, respeitar o outro em sua diferença.

\section{Referências}

American Psychiatric Association. (1994). Diagnostic and Statistical Manual of Mental Disorders (4nd ed.). Washington, DC: Author. Bergson, H. (2005). A evolução criadora. São Paulo, SP: Martins Fontes. (Original publicado em 1907) 
De-Nardin, M.H.; Sordi, R.O. "Um estudo sobre as formas de atenção na sala de aula e suas implicações para a aprendizagem"

Bergson, H. (1999). Matéria e memória: Ensaio sobre a relação do corpo com o espírito (2. ed.). São Paulo, SP: Martins Fontes. (Original publicado em 1896)

Corea, C., \& Lewkowicz, I. (2005). Pedagogía del aburrido. Escuelas destituidas, familias perplejas. Buenos Aires, Argentina: Paidós.

Crary, J. (1999). Suspensions of perception (attention, spectacle, and modern culture). Cambridge, MA: MIT Press.

Deleuze, G. (1988). Diferença e repetição. Rio de Janeiro, RJ: Graal.

Deleuze, G. (1999). Bergsonismo. São Paulo, SP: Ed.34.

Foucault, M. (1985). História da Sexualidade 3: O cuidado de si (6. ed.). Rio de Janeiro, RJ: Graal.

Foucault, M. (2004). Ética, sexualidade, política: Vol. 5. Ditos e Escritos. Rio de Janeiro, RJ: Forense Universitária.

Kastrup, V. (1999). A invenção de si e do mundo: Uma introdução do tempo e do coletivo no estudo da cognição. Campinas, SP: Papirus.

Kastrup, V. (2004). A aprendizagem da atenção na cognição inventiva. Psicologia \& Sociedade, 16(3), 7-16.

Maturana, H. (1998). Emoções e linguagem na educação e na política. Belo Horizonte, MG: Editora da Universidade Federal de Minas Gerais.

Maturana, H. (2001). A ontologia da realidade. Belo Horizonte, MG: Editora da Universidade Federal de Minas Gerais.

Maturana, H., \& Varela, F. J. (2002). De máquinas e seres vivos: Autopoiese - a organização do vivo (3. ed.). Porto Alegre, RS: Artmed. (Original publicado em 1973)

Sordi, R. (1999). A comunicação professor-aluno: Uma contribuição ao estudo sobre a construção do conhecimento. Tese de Doutorado não-publicada, Universidade Federal do Rio Grande do Sul, Programa de Pós-Graduação em Educação, Porto Alegre, RS.
Varela, F. (2003). O reencantamento do concreto. Cadernos de Subjetividade, 1(1), 72-86.

Varela, F., Thompson, E., \& Rosch, E. (2003). A mente incorporada: Ciências cognitivas e experiência humana. Porto Alegre, RS: Artmed.

Maria Helena De-Nardin é pedagoga e psicopedagoga. Mestranda do Programa de PósGraduação em Psicologia Social da Universidade Federal do Rio Grande do Sul - UFRGS. Endereço para correspondência: Rua Ramiro Barcellos, 2600, térreo (sala 13) - CEP 90035-003 - Porto Alegre, RS.

$$
\text { denardin@globo.com }
$$

Regina Sordi é psicóloga e psicopedagoga. Professora adjunta do Instituto de Psicologia e da Pós-Graduação em Psicologia Social e Institucional da UFRGS.

sordi.voy@zaz.com.br

\section{Um estudo sobre as formas de atenção na sala de aula e suas implicações para a aprendizagem}

Maria Helena De-Nardin e Regina Orgler Sordi

Recebido: 18/05/2006

$1^{\text {a }}$ revisão: 22/08/2006

Aceite final: 15/09/2006 